\title{
Stigma as a barrier to family planning use among married youth in Ethiopia
}

\author{
Aparna Jain $^{1 \star}$, Hussein Ismail ${ }^{2}$, Elizabeth Tobey $^{1}$ and Annabel Erulkar ${ }^{2}$ \\ ${ }^{1}$ Population Council, Washington DC, USA and ${ }^{2}$ Population Council, Addis Ababa, Ethiopia \\ ${ }^{\star}$ Corresponding author. Email: apjain@popcouncil.org
}

(Received 22 March 2018; revised 30 August 2018; accepted 31 August 2018; First published online 23 October 2018)

\begin{abstract}
Nearly 33 million female youths have an unmet need for voluntary family planning (FP), meaning they are sexually active and do not want to become pregnant. In Ethiopia, age at marriage remains low: $40 \%$ and $14 \%$ of young women aged 20-24 were married by the ages of 18 and 15 , respectively. Despite increases in FP use by married 15- to 24 -year-olds from $5 \%$ in 2000 to $37 \%$ in 2016 , unmet need remains high at $19 \%$. Supply-and-demand factors have been shown to limit FP use, yet little is known about how stigma influences FP use among youth. This study validates an anticipated stigma (expectation of discrimination from others) index and explores its effect on unmet need. A cross-sectional survey was implemented with 15- to 24-year-old female youth in Ethiopia in 2016. The analytic sample included married respondents with a demand (met and unmet need) for FP $(n=371)$. A five-item anticipated stigma index (Cronbach's $\alpha=0.66$ ) was developed using principal component factor analysis. These items related to fear, worry and embarrassment when accessing FP. The findings showed that $30 \%$ agreed with at least one anticipated stigma question; $44 \%$ had an unmet need; $58 \%$ were married before age 18 ; and $100 \%$ could name an FP method and knew where to obtain FP. In multivariate regression models, youth who experienced anticipated stigma were significantly more likely to have an unmet need, and those who lived close to a youth-friendly service (YFS) site were significantly less likely to have an unmet need. Interventions should address anticipated stigma while focusing on social norms that restrict married youth from accessing FP; unmet need may be mitigated in the presence of a YFS; and the anticipated stigma index appears valid and reliable but should be tested in other countries and among different adolescent groups.
\end{abstract}

Keywords: Family Planning; Stigma; Youth

\section{Introduction}

Among adolescent girls and young women aged 15-24, 33 million in 61 countries are estimated to have an unmet need for voluntary family planning (FP) (MacQuarrie, 2014). Those with an unmet need are sexually active women who do not wish to become pregnant but who are not using any method of contraception. Over the past several decades, unmet need has declined in many of these countries but only one in two married adolescent girls' demand for FP (unmet need plus current use) has been satisfied. The youngest appear to be the most vulnerable, as 15- to 16-year-old married girls experience the greatest unmet need for FP (MacQuarrie, 2014). Factors that prevent youth from accessing and using voluntary family planning and reproductive health $(\mathrm{FP} / \mathrm{RH})$ services have been documented extensively and include restrictive laws and policies; provider attitude, bias and judgement; inconvenient times, locations and fees; limited range of contraceptive method availability; perceptions of a lack of confidentiality; sociocultural 
pressures for early childbearing; fear of being seen; and embarrassment with procurement (Biddlecom et al., 2007b; Chandra-Mouli et al., 2013, Kennedy et al., 2013; Abajobir \& Seme, 2014; Abebe \& Awoke, 2014; Sulemana \& Badasu, 2015; HIPs, 2015; Ayehu et al., 2016; Motuma et al., 2016).

In a literature review of youth's perceptions of barriers to accessing FP/RH services (Bender \& Fulbright, 2013), personal factors such as fear, embarrassment or insecurity were found to delay health-seeking behaviours and cause fear of ruined reputation. Lack of confidentiality at health centres was also a recurring barrier to FP/RH services access. In sub-Saharan Africa, the fear of being seen and lack of confidentiality have been shown to be barriers to FP/RH service use (Sulemana \& Badasu, 2015; Ayehu et al., 2016; Nyblade et al., 2017).

Married young women and girls face unique barriers to accessing FP/RH services and are often neglected in programmes (Mekbib et al., 2005; Bruce \& Chong, 2006). Recently married girls and young women face intense social pressure to bear a child early in marriage (Rivera et al., 2001; Bruce \& Chong, 2006). Even after the first birth, however, married youth still face barriers to accessing services. Because most have left school, married adolescents and young women in sub-Saharan Africa are often socially isolated and have restricted mobility, which creates barriers to obtaining care (Bruce \& Chong, 2006; Biddlecom et al., 2007a). A qualitative study in Guatemala found that barriers preventing married young women aged 20-24 from accessing FP services included lack of knowledge about methods, fear of side-effects and infertility, beliefs that contraception is a sin, fear of social chastisement and husband's opposition (Richardson et al., 2016). In Uganda, a qualitative study of newly married adolescents found that even though couples communicated about timing of births, male opposition was a barrier to using family planning (Adams et al., 2013).

Access to voluntary contraceptive services is particularly important among married youth in Ethiopia where $40 \%$ of young women aged 20-24 were married by age 18 and $14 \%$ were married by age 15 (Central Statistical Agency \& ICF, 2016a). Early age at marriage prevails in conservative areas, and when coupled with high rates of youth childbearing (55\% of young women aged $20-24$ have given birth; Central Statistical Agency \& ICF, 2016a), Ethiopian youth are particularly vulnerable to maternal mortality and morbidity. In addition, despite the rise in voluntary use of modern contraceptive methods from 5\% in 2000 to $37 \%$ in 2016 among married 15- to 24-yearolds, unmet need for family planning among this group remains substantial at $19 \%$. Among 15- to 24-year-olds with a demand for family planning, unmet need is higher among those who are married (37\%) than among those who have never been married (29\%) (Central Statistical Agency \& ICF, 2016b). Furthermore, nearly a quarter of pregnant 15- to 24-year-olds felt that their pregnancy was mistimed or unwanted (Central Statistical Agency \& ICF, 2016a). Given this context, research on the barriers to accessing FP/RH services is needed and should be part of broader efforts to improve the health and agency of young women and girls, along with interventions aimed at delaying the age at marriage.

\section{Stigma and $\mathrm{FP} / \mathrm{RH}$ service utilization}

Goffman (1963) defined stigma as a characteristic or attribute of an individual that society rejects and discredits. Since then, different types of stigma have been described including: internalized stigma (the acceptance of society's exclusionary views towards oneself); anticipated stigma (the belief that others will discriminate against oneself: Weiss, 2008; Quinn \& Chaudoir, 2009); and enacted stigma or discrimination (the experience of unfair treatment by others: Scambler \& Hopkins, 1986). Stigma can prevent individuals from seeking help or health services and can lead to thoughts of suicide, depression or self-isolation from social settings.

Stigma has often been described in the fields of epilepsy (Scambler, 2004; Bautista et al., 2015), HIV (Parker \& Aggleton, 2003; Sandelowski et al., 2004; Yebei et al., 2008; Jiménez et al., 2010; Chambers et al., 2015), abortion (Norris et al., 2011; Cockrill et al., 2013; Gelman et al., 2017), 
mental health (Wahl, 1999; Corrigan, 2004; King et al., 2007), sexual violence (Coffey et al., 1996; Murray et al., 2018), hepatitis C (Butt et al., 2007; Lekas et al., 2011) and obesity (Puhl \& Huer, 2010; Brewis et al., 2017). The concept of stigma, however, has yet to be fully developed or applied to married girls and young women's need for voluntary contraceptives and may be an important barrier to use. For example, a young married girl who wants to postpone her first birth may want to use a contraceptive method but anticipates negative attitudes (such as judgement from health providers) or discrimination (like verbal or physical abuse from husband) or feels shame for wanting to use contraception that prevents her from accessing contraceptive services.

Two recent qualitative studies in Tanzania (Nyblade et al., 2017) and Ghana (Hall et al., 2015) looked at different dimensions of stigma and $\mathrm{FP} / \mathrm{RH}$, primarily among unmarried girls. In the Tanzanian study, a limited number of respondents had ever personally experienced the process of obtaining a contraceptive method. Therefore, the barriers identified to accessing services were related to perceptions of service delivery and anticipated stigma if they were to seek services, including: fear of lack of confidentiality, denial of services, excessive questioning, negative labelling or parental supervision at visit.

The Ghana study, on the other hand, identified enacted and internalized stigma associated with pregnancy and childbearing, among other themes, but not in relation to contraceptive methods. Hall et al. (2017) went on to develop and validate an adolescent FP/RH stigma measure that included subscales for enacted and internalized stigma based on their qualitative findings. While their measures of enacted and internalized stigma included several items associated with contraceptives, most of the questions asked were about respondents' beliefs and their perceptions of community members' perceptions as opposed to respondents' own internalization of FP/RH issues or experiences of discrimination.

Anticipated stigma (expectation of discrimination from others) has been shown to be a barrier to accessing services in the context of mental health (Iversen et al., 2011) and intimate partner violence (Overstreet \& Quinn, 2013) but not family planning. Therefore, the current study measures and validates an anticipated stigma index associated with FP need, assesses anticipated stigma among both married FP users and married non-users, and explores its effect on unmet need after adjusting for other barriers to FP use.

\section{Methods}

\section{Data}

The study analysed data from a cross-sectional household survey in five Ethiopian regions: Amhara, Benishangul-Gumuz, Oromia, SNNP and Tigray. Data were collected from 15- to 24-year-old girls and young women between January and July 2016. The sample was designed to measure the effect of distance to a youth-friendly service (YFS) site on utilization of FP, HIV and maternal health services. The Regional Health Bureaus listed 247 YFS sites in rural areas. Five per cent of YFS sites and one non-YFS site were randomly selected as the sampling frame from each region using probability proportional to size. Fourteen YFS sites and five non-YFS sites were chosen across the five regions.

A stratified, two-stage cluster design was employed. Enumeration areas (EAs) were the primary sampling unit (PSUs) in the first stage. The EAs were stratified by distance from the YFS site $(<5 \mathrm{~km}$ or $5 \mathrm{~km}$ to $<10 \mathrm{~km})$ and three EAs were selected from each stratum. One EA was also selected from within $5 \mathrm{~km}$ of each non-YFS site. Eligible households were randomly selected, and one eligible respondent per household was selected using a KISH grid (Kish, 1949). A detailed description of the sampling strategy is available in the study report (Jain et al., 2017). The total number of females interviewed was 1329 with a response rate of approximately $94 \%$.

Questionnaires obtained information on a range of issues including social cohesion, autonomy, attitudes towards FP, fertility intentions, use of FP, maternal health and basic health services and awareness and use of services at YFS sites. Questionnaires were translated into 
multiple languages including Amharic, Tigrinya and Oromo. Informed consent was obtained from all respondents in the survey.

\section{Variables}

\section{Dependent variable}

The outcome variable was 'unmet need for family planning' calculated using the revised definition of unmet need (Bradley et al., 2012). The categories of need are: 1) met need= females who are currently using a contraceptive method; 2) no need=currently pregnant females who wanted their pregnancy at that time and non-pregnant females who would like to have a child in the next 2 years; and 3) unmet need=non-users of any method who reported that they do not want to have any more children, would like their next child in more than 2 years or were unsure of the timing, and currently pregnant women who reported that they did not want the pregnancy at all or wanted it later. Following the terminology used in the literature, total demand equals the sum of current contraceptive users (met need) plus those with an unmet need.

\section{Anticipated stigma index}

The main predictor variable was a composite index that captured anticipated stigma. The index was developed using a pool of fourteen questions that were developed based on preliminary findings from a qualitative study conducted with youth in Tanzania (Nyblade et al., 2017), in addition to the researchers' knowledge of FP service barriers among sexually active Ethiopian youth. Respondents were asked to answer a series of attitudinal questions on a 4-point Likert scale with answers ranging from 'strongly agree' to 'strongly disagree'. They were prompted with the following statement: 'Suppose that you were planning to get services related to FP next week. Please keep this scenario in mind and tell me if you: strongly disagree, disagree, agree or strongly agree with the following statements.' Principal component factor analysis was used to reduce the items. Items were considered for removal if their factor loading was less than 0.50 (Matsunaga, 2015). The reliability of the index was tested using Cronbach's $\alpha$ with a cut-off of 0.60 (Loewenthal, 2001). The five items in the index were combined to form a composite score ranging from 0 to 5 , which was then dichotomized into $0=$ no agreement across all five items and $1=$ agreement on at least one item.

\section{Other independent variables}

Several additional variables were considered, including distance of household from a YFS or nonYFS site to assess physical access to, and availability of, quality services, women's participation in decision-making to assess empowerment, ownership of personal savings to assess financial autonomy and visiting a mosque/church in their leisure time to assess religiosity. The decisionmaking measure was developed based on four items and came from the question: Who makes decisions about (1) your health; (2) school attendance; (3) who you spend time with; and (4) about where you go?' Each item was dichotomized into whether the respondent had any say in the decision (independently or jointly with someone else such as her husband or extended family member) or whether she had no say in the decision. A composite index was formed ranging from 0 to 4 , where 4 indicates the respondent had a say in all four aspects of decision-making. This score was dichotomized into no/low (0 to 3 ) involvement and all (4) involvement.

\section{Analysis}

The sample was restricted to married youth with a demand for contraception, i.e. with a met or unmet need for FP. Respondents reporting no need for FP were excluded from the analysis because they were youth who were either pregnant and wanted the child at that time or who wanted to get pregnant in the next 2 years. Unmarried respondents were also excluded because the majority reported that they had not had sex. 
Descriptive statistics were calculated for respondent characteristics. Bivariate models of all covariates against the outcome variable were conducted using Pearson's $\chi^{2}$ test for categorical variables and $t$-tests for continuous variables. Multivariate logistic regression was used, adjusting the association for age, parity, ever attended school, religion and region of residence. Variables that were statistically significant in the bivariate analysis were included in the multivariate model but in some instances non-significant variables were included if they had theoretical importance. All statistical analyses were conducted in Stata Version 13 (StataCorp, 2013).

\section{Results}

\section{Respondents' characteristics}

The total number of married youth aged 15-24 years with a demand for contraception was 371: $56 \%(n=207)$ with a met need and $44 \%(n=164)$ with an unmet need. Most married youth were aged $20-24(82 \%)$, had at least one child (83\%) and had attended school (73\%) (Table 1). Over half of the respondents were married before the age of 18 (58\%, data not shown) and $21 \%$ were at least 10 years younger than their husband.

\section{Anticipated stigma index}

Responses on each of the fourteen items were recoded as binary variables: 1 for agree and strongly agree and 0 otherwise. The percentage of respondents who agreed with each item in addition to the factor loadings are presented in Table 2. Two factors formed: 1) anticipated stigma, which included measures related to worry, fear and embarrassment; and 2) desire to be accompanied to a facility for FP services. The second factor was explored in the analysis but was excluded from the results because of the low $\alpha$ score and lack of significant relationships.

The percentage of respondents who agreed with the five items of the anticipated stigma index are presented in Fig. 1. Eight per cent of youth agreed that they would be embarrassed to discuss FP with a provider and $9 \%$ agreed that they would be embarrassed about wanting more FP information. Ten per cent agreed that they would worry if people in their community learned that they needed contraception while $14 \%$ agreed that they would worry if their parents learned of their FP needs. Twelve per cent feared being seen at the facility. Overall, $30 \%$ of respondents agreed with at least one of these five items.

Figure 2 shows the results of the composite score for the anticipated stigma index. Most respondents reported no anticipated stigma (70\%). Agreement with one item was $17 \%$ and agreement across all five items was $1 \%$.

To test criterion validity of the anticipated stigma index, the known-group validity method was used (Netemeyer et al., 2003) and differences in mean scores on the anticipated stigma index were compared among respondents who visited and did not visit a health facility for FP services in the 6 months preceding the survey. The mean score on the anticipated stigma index was 0.36 among respondents who sought FP services and 0.66 among those who did not 6 months preceding the survey (data not shown). The difference in these means was statistically significant with a $p$-value of 0.004 .

\section{Bivariate analysis}

Table 3 presents the bivariate analysis of unmet need for FP by anticipated stigma index, distance from a YFS site, involvement in decision-making, own personal savings, time spent at mosque/ church and respondent characteristics. Youth who agreed with the anticipated stigma statements were more likely to have an unmet need. Youth who lived less than $5 \mathrm{~km}$ from a YFS site, who had their own savings and who had spent time at a mosque or church were less likely to have an unmet need. Unmet need appeared to increase with number of living children and to decrease 
Table 1. Percentage distribution of married adolescent youth aged $15-24$ years by characteristics $(N=371)$

\begin{tabular}{|c|c|}
\hline & $\%$ \\
\hline \multicolumn{2}{|l|}{ Age } \\
\hline $15-19$ & 17.8 \\
\hline $20-24$ & 82.2 \\
\hline \multicolumn{2}{|l|}{ Parity $^{a}$} \\
\hline No children & 17.3 \\
\hline One child & 42.9 \\
\hline Two or more children & 38.0 \\
\hline \multicolumn{2}{|l|}{ Age at marriage ${ }^{a}$} \\
\hline $10-14$ & 11.3 \\
\hline $15-19$ & 76.6 \\
\hline $20-24$ & 11.3 \\
\hline \multicolumn{2}{|l|}{ Age difference with spouse ${ }^{a}$} \\
\hline Same age or older & 0.8 \\
\hline 1-4 years younger & 26.7 \\
\hline 5-9 years younger & 43.7 \\
\hline$\geq 10$ years younger & 21.0 \\
\hline \multicolumn{2}{|l|}{ Education } \\
\hline Never attended school & 27.5 \\
\hline Ever attended school & 72.5 \\
\hline \multicolumn{2}{|l|}{ Religion $^{a}$} \\
\hline Orthodox Christian & 51.2 \\
\hline Muslim & 40.2 \\
\hline Other & 8.6 \\
\hline \multicolumn{2}{|l|}{ Region } \\
\hline Tigray & 16.4 \\
\hline Amhara & 32.4 \\
\hline Oromia & 26.1 \\
\hline Benishangul-Gumuz & 9.2 \\
\hline SNNP & 15.9 \\
\hline
\end{tabular}

aproportions do not add up to $100 \%$ because of missing values.

when youth marry later in life. Unmet need was also higher for youth who had never attended school.

Two known barriers to contraceptive use - knowledge of at least one FP method and where to obtain FP services - were excluded from the analysis because $100 \%$ of respondents could name at 
Table 2. Factor loadings for anticipated stigma and desire to be accompanied indices $(N=371)$

\begin{tabular}{|c|c|c|c|}
\hline $\begin{array}{l}\text { Suppose that you were planning to get services related to family planning next week. } \\
\text { Please keep this scenario in mind and tell me if you: strongly disagree, disagree, } \\
\text { agree or strongly agree with the following statements. }\end{array}$ & $\begin{array}{c}\% \\
\text { agree }\end{array}$ & $\begin{array}{l}\text { Factor 1: } \\
\text { Anticipated } \\
\text { stigma }\end{array}$ & $\begin{array}{l}\text { Factor 2: } \\
\text { Accompany }\end{array}$ \\
\hline a) I would need more information about FP services & 97.6 & -0.072 & 0.270 \\
\hline b) I would know where to go to get FP services & 99.2 & 0.104 & 0.143 \\
\hline c) I would want my boyfriend/partner/husband to come with me to get FP & 77.1 & 0.009 & 0.554 \\
\hline d) I would feel embarrassed about wanting more information about FP services & 8.9 & 0.563 & -0.091 \\
\hline e) I would want a female family member to come with me to get FP & 69.5 & 0.058 & 0.781 \\
\hline f) I would be afraid of being seen by someone I knew at the facility & 11.9 & 0.662 & -0.012 \\
\hline $\begin{array}{l}\text { g) I would be worried about what my parents would say if they found out that I } \\
\text { needed FP services }\end{array}$ & 14.3 & 0.627 & 0.097 \\
\hline h) My boyfriend/partner/husband would support me in my decision to get FP & 88.1 & -0.149 & 0.265 \\
\hline i) I would want a female friend to come with me to get FP & 70.9 & 0.029 & 0.788 \\
\hline j) I would be worried that religious leaders in my community would not support me & 31.5 & 0.188 & 0.029 \\
\hline $\begin{array}{l}\text { k) I would be worried about what people in my community would say about me if } \\
\text { they found out I needed FP }\end{array}$ & 10.0 & 0.698 & 0.045 \\
\hline $\begin{array}{l}\text { l) I would trust that FP providers will keep my personal and health information } \\
\text { confidential }\end{array}$ & 91.9 & -0.206 & 0.263 \\
\hline m) I would feel embarrassed talking to a provider about FP & 7.6 & 0.597 & 0.005 \\
\hline n) I would be worried that the cost of the FP services would be too high & 13.8 & 0.449 & 0.122 \\
\hline Cronbach's $\alpha$ & & 0.66 & 0.53 \\
\hline
\end{tabular}

The factor loadings forming the indices are in bold.

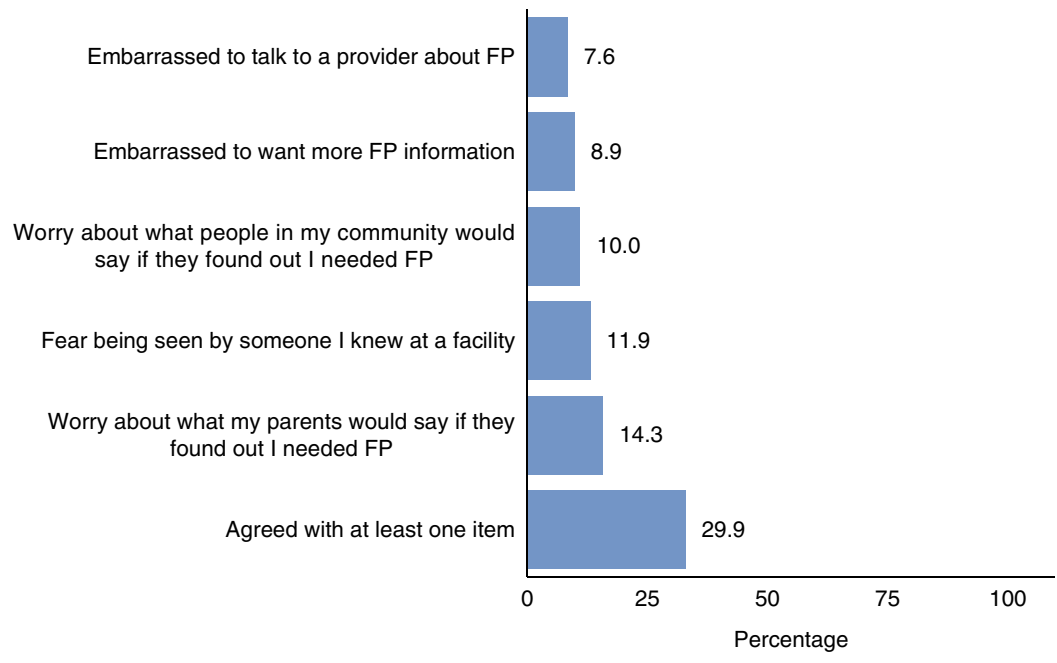

Figure 1. Agreement with anticipated stigma statements by 15 - to 24 -year-old married females. 
512 A. Jain et al.

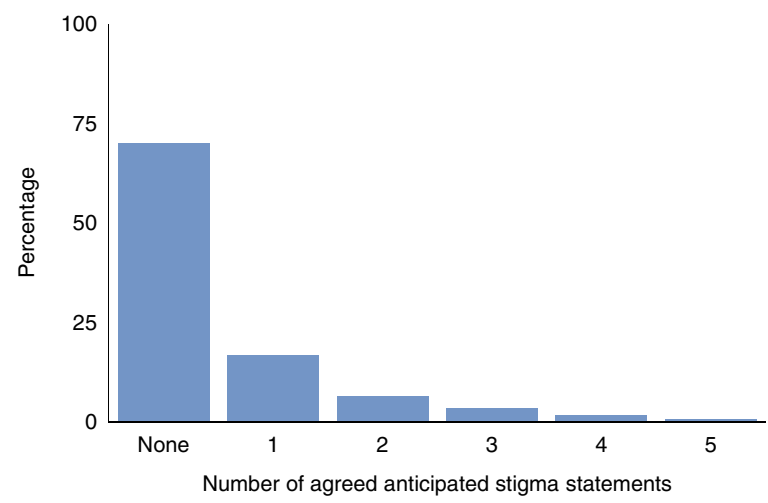

Figure 2. Percentage distribution of 15- to 24-year-old married females by number of agreed anticipated stigma statements.

Table 3. Bivariate analysis of unmet need for family planning $(N=371)$

\begin{tabular}{|c|c|c|c|}
\hline & $\begin{array}{l}\text { Met need } \\
(\%)\end{array}$ & $\begin{array}{l}\text { Unmet need } \\
(\%)\end{array}$ & $\begin{array}{c}\text { Total } \\
(N)\end{array}$ \\
\hline \multicolumn{4}{|c|}{ Anticipated stigma index (5 items) ${ }^{\star \star}$} \\
\hline No stigma & 60.4 & 39.6 & 260 \\
\hline Stigma on $\geq 1$ item & 45.1 & 54.9 & 111 \\
\hline \multicolumn{4}{|l|}{ Distance from YFS } \\
\hline$<5 \mathrm{~km}$ from YFS & 62.8 & 37.2 & 156 \\
\hline 5-10 km from YFS & 52.0 & 48.0 & 152 \\
\hline$<5 \mathrm{~km}$ from non-YFS & 47.6 & 52.4 & 63 \\
\hline \multicolumn{4}{|c|}{ Involvement in decision-making } \\
\hline None or some & 42.5 & 57.5 & 134 \\
\hline All & 45.2 & 54.8 & 230 \\
\hline Missing & 42.9 & 57.1 & 7 \\
\hline \multicolumn{4}{|l|}{ Has own savings** } \\
\hline No & 52.9 & 47.1 & 310 \\
\hline Yes & 71.7 & 28.3 & 60 \\
\hline \multicolumn{4}{|c|}{ Spent time at mosque/church* } \\
\hline No & 43.8 & 56.2 & 96 \\
\hline Yes & 60.0 & 40.0 & 275 \\
\hline \multicolumn{4}{|l|}{ Age } \\
\hline $15-19$ & 50.0 & 50.0 & 66 \\
\hline $20-24$ & 57.1 & 42.9 & 305 \\
\hline \multicolumn{4}{|l|}{ Parity** } \\
\hline No children & 67.2 & 32.8 & 64 \\
\hline
\end{tabular}


Table 3. Continued

\begin{tabular}{|c|c|c|c|}
\hline & $\begin{array}{c}\text { Met need } \\
(\%)\end{array}$ & $\begin{array}{c}\text { Unmet need } \\
(\%)\end{array}$ & $\begin{array}{c}\text { Total } \\
(N)\end{array}$ \\
\hline One child & 59.1 & 40.9 & 159 \\
\hline Two or more children & 46.1 & 53.9 & 141 \\
\hline Missing & 71.4 & 28.6 & 7 \\
\hline \multicolumn{4}{|l|}{ Age at marriage } \\
\hline $10-14$ & 47.6 & 52.4 & 42 \\
\hline $15-19$ & 54.6 & 45.4 & 284 \\
\hline $20-24$ & 73.8 & 26.2 & 42 \\
\hline Missing & 33.3 & 66.7 & 3 \\
\hline \multicolumn{4}{|l|}{ Education $^{\star \star \star}$} \\
\hline Never attended school & 39.2 & 60.8 & 102 \\
\hline Ever attended school & 62.1 & 37.9 & 269 \\
\hline \multicolumn{4}{|l|}{ Religion ${ }^{\star \star \star}$} \\
\hline Orthodox Christian & 66.8 & 33.2 & 190 \\
\hline Muslim & 41.6 & 58.4 & 149 \\
\hline Other & 56.3 & 43.7 & 32 \\
\hline \multicolumn{4}{|l|}{ Region } \\
\hline Tigray & 44.3 & 55.7 & 61 \\
\hline Amhara & 64.2 & 35.8 & 120 \\
\hline Oromia & 55.7 & 44.3 & 97 \\
\hline Benishangul-Gumuz & 61.8 & 38.2 & 34 \\
\hline SNNP & 47.5 & 52.5 & 59 \\
\hline
\end{tabular}

${ }^{*} p \leq 0.05 ;{ }^{* *} p \leq 0.01 ;{ }^{* \star *} p \leq 0.001$.

least one FP method and knew a place where they could get it. Among respondents with an unmet need, $45 \%$ had used a contraceptive method in the past, and of these past users, $34 \%$ intended to use a contraceptive method in the next 12 months (data not shown).

\section{Multivariate analysis}

Unadjusted and adjusted odds ratios (OR) for the effect of anticipated stigma on unmet need for FP are presented in Table 4. The unadjusted OR for the effect of anticipated stigma index on unmet need was 1.86 (95\% CI: 1.19-2.91). The adjusted OR increased in magnitude to 1.97 and remained significant (95\% CI: 1.16-3.36). Youth who lived less than $5 \mathrm{~km}$ from a non-YFS site were significantly more likely to have an unmet need for FP compared with those who lived less than $5 \mathrm{~km}$ from a YFS site (AOR: 2.11; 95\% CI: 1.04-4.30) The lincom command was run to compare youth living between 5 and $10 \mathrm{~km}$ from a YFS site with youth living less than $5 \mathrm{~km}$ from a non-YFS site and found that youth living further away from a YFS site were less likely to have an unmet need. However, this relationship was not statistically significant. 
514 A. Jain et al.

Table 4. Unadjusted and adjusted Odds Ratios (ORs) of unmet need for family planning

\begin{tabular}{|c|c|c|c|c|}
\hline & $\begin{array}{c}\text { Unadjusted } \\
\text { OR }\end{array}$ & $95 \% \mathrm{Cl}$ & $\begin{array}{l}\text { Adjusted } \\
\text { OR }\end{array}$ & $95 \% \mathrm{Cl}$ \\
\hline \multicolumn{5}{|c|}{ Anticipated stigma index (5 items) } \\
\hline No stigma & Ref. & & Ref. & \\
\hline Stigma on $\geq 1$ item & $1.86^{\star \star}$ & $(1.19-2.91)$ & $1.97^{\star}$ & $(1.16-3.36)$ \\
\hline \multicolumn{5}{|l|}{ Distance from YFS } \\
\hline$<5 \mathrm{~km}$ from YFS & Ref. & & Ref. & \\
\hline 5-10 km from YFS & 1.56 & $(0.99-2.46)$ & 1.53 & $(0.91-2.58)$ \\
\hline$<5 \mathrm{~km}$ from non-YFS & $1.86^{\star}$ & $(1.02-3.36)$ & $2.11^{\star}$ & $(1.04-4.30)$ \\
\hline \multicolumn{5}{|l|}{ Involvement in decisions } \\
\hline None/some & Ref. & & Ref. & \\
\hline All & 1.12 & $(0.73-1.71)$ & 1.35 & $(0.79-2.31)$ \\
\hline \multicolumn{5}{|l|}{ Own savings } \\
\hline No & $2.25^{\star \star}$ & $(1.23-4.12)$ & 1.60 & $(0.79-3.21)$ \\
\hline Yes & Ref. & & Ref. & \\
\hline \multicolumn{5}{|c|}{ Spent time at mosque/church } \\
\hline No & Ref. & & Ref. & \\
\hline Yes & $0.52^{\star \star}$ & $(0.32-0.83)$ & 0.68 & $(0.39-1.21)$ \\
\hline \multicolumn{5}{|l|}{ Age } \\
\hline $15-19$ & 1.33 & $(0.78-2.26)$ & 1.87 & $(0.92-3.82)$ \\
\hline $20-24$ & Ref. & & Ref. & \\
\hline \multicolumn{5}{|l|}{ Parity } \\
\hline No children & Ref. & & Ref. & \\
\hline One child & 1.42 & $(0.77-2.61)$ & 1.32 & $(0.63-2.67)$ \\
\hline Two or more children & $2.39^{\star \star}$ & $(1.29-4.44)$ & 1.89 & $(0.81-4.40)$ \\
\hline \multicolumn{5}{|l|}{ Age at marriage } \\
\hline $10-14$ & Ref. & & Ref. & \\
\hline $15-19$ & 0.76 & $(0.40-1.45)$ & 0.71 & $(0.32-1.57)$ \\
\hline $20-24$ & $0.32^{\star}$ & $(0.13-0.81)$ & 0.58 & $(0.19-1.89)$ \\
\hline \multicolumn{5}{|l|}{ Education } \\
\hline Never attended school & $2.54^{\star \star \star}$ & $(1.59-4.05)$ & $2.73^{\star \star}$ & $(1.54-4.83)$ \\
\hline Ever attended school & Ref. & & Ref. & \\
\hline \multicolumn{5}{|l|}{ Religion } \\
\hline Orthodox Christian & Ref. & & Ref. & \\
\hline
\end{tabular}


Table 4. Continued

\begin{tabular}{|c|c|c|c|c|}
\hline & $\begin{array}{c}\text { Unadjusted } \\
\text { OR }\end{array}$ & $95 \% \mathrm{Cl}$ & $\begin{array}{l}\text { Adjusted } \\
\text { OR }\end{array}$ & $95 \% \mathrm{Cl}$ \\
\hline Muslim & $2.83^{\star \star \star}$ & $(1.81-4.41)$ & $4.25^{\star \star \star}$ & $(2.22-8.15)$ \\
\hline Other & 1.57 & $(0.73-3.36)$ & $3.62^{\star \star}$ & $(1.37-9.61)$ \\
\hline \multicolumn{5}{|l|}{ Region } \\
\hline Tigray & Ref. & & Ref. & \\
\hline Amhara & $0.44^{\star}$ & $(0.24-0.83)$ & $0.26^{\star \star \star}$ & $(0.12-0.55)$ \\
\hline Oromia & 0.63 & $(0.33-1.20)$ & $0.20^{\star \star \star}$ & $(0.08-0.48)$ \\
\hline Benishangul-Gumuz & 0.49 & $(0.21-1.16)$ & $0.19^{\star \star}$ & $(0.06-0.56)$ \\
\hline SNNP & 0.88 & $(0.43-1.80)$ & $0.25^{\star \star}$ & $(0.09-0.67)$ \\
\hline
\end{tabular}

Ref., reference category.

${ }^{\star} p \leq 0.05 ;{ }^{* *} p \leq 0.01 ;{ }^{* \star} p \leq 0.001$.

Significant associations were maintained in the adjusted logistic model for unmet need by education and religion. The Hosmer-Lemeshow goodness-of-fit test was applied and showed that this model fitted the data reasonably well.

\section{Discussion}

The results of this study show that among married female youth in Ethiopia, anticipated stigma is significantly associated with an unmet need for voluntary family planning. This effect remains significant after adjusting the association for other known barriers to FP use, including proximity to a YFS facility. The anticipated stigma measures include embarrassment discussing contraceptives with providers, worry about parental or other community members' attitudes towards married youth who need FP and fear of being seen when accessing contraceptive services. These issues stem from broader social and community-level opinions of married girls' use of contraceptives. In Ethiopia, where early marriage remains deeply rooted in tradition and pressures to demonstrate fertility are high, the ability to access FP/RH services and make decisions about ones' own health is still limited, and the reproductive health of married girls and young women can suffer as a result (Shaw, 2009). It is therefore critical that efforts to increase access to FP/RH services are comprehensive, including interventions to delay the age at marriage and increase the autonomy of married girls and young women (Erulkar et al., 2017).

The study results also show that youth who live close to a non-YFS site $(<5 \mathrm{~km})$ are significantly more likely to have an unmet need compared with youth who live close to a YFS site $(<5 \mathrm{~km})$. In Ethiopia, YFS sites have been scaled-up to over 300 health facilities across the country (Pathfinder International, 2012). Youth-friendly services aim to reduce stigma specifically through peer-to-peer comprehensive counselling on FP/RH and life skills for youth and peer educator-led awareness activities for parents, youth and community leaders (Pathfinder International, 2016). Creating YFS services also involves training providers and support staff to be non-judgemental, to be technically competent in adolescent-specific needs and to reduce stigma at facilities. While improving service quality and reducing provider bias and judgement towards youth's access of FP services is important, it alone is not sufficient to increase use of services (Mmari \& Magnani, 2003).

Interventions that aim to increase demand for voluntary $\mathrm{FP} / \mathrm{RH}$ services have also been met with varying degrees of success (Denno et al., 2015). In Ethiopia, community-based programmes 
to delay age at marriage, support girls to stay in or re-enter school and provide economic incentives to keep girls in school have been successful (Erulkar \& Muthengi, 2009; Muthengi \& Erulkar, 2011; Erulkar et al., 2017). Following the success of these programmes, holding community dialogues to change social norms about young people's use of FP/RH services, in addition to changing norms about age at marriage and educational attainment, may be a promising intervention to reduce the barriers to contraceptive access caused by anticipated stigma. However, working on changing societal norms around married youth and FP will take time, and these findings suggest that interventions need to explore how to support and empower married youth to strategize effective ways of accessing services in an environment where societal/community norms may expect them not to use family planning.

This study also showed that among married youth with an unmet need, $45 \%$ had used a contraceptive method previously. Further analysis showed that $42 \%$ of previous FP users with an unmet need strongly agreed with the statement 'my boyfriend/partner/husband would support me in my decision to get FP' compared with $24 \%$ of never users with an unmet need, and this difference was statistically significant. This suggests that married youth who were previous contraceptive users were able to overcome family - specifically husband or partner - barriers to use services. In addition, previous FP users with an unmet need were more likely to agree with the anticipated stigma index, have personal savings and have ever attended school compared with never users. Furthermore, among the previous FP users with an unmet need, 34\% reported that they intend to use a contraceptive method in the next 12 months while $66 \%$ said they intend to use in more than 2 years, were unsure of the timing or did not intend to use in the future. Future research should seek to understand why these past users with an unmet need do not intend to use in the future, especially for reasons other than to get pregnant, so that interventions can be designed to support them to resume FP use (Jain et al., 2013).

There are several limitations to this study. The first is that since this was a cross-sectional survey, causality could not be determined, and the results need to be interpreted accordingly. This also limited the ability to test the predictive validity of the anticipated stigma index against future behaviours. Another limitation is that there may be a certain amount of respondent bias where respondents are under-reporting contraceptive use, and therefore over-reporting unmet need, due to the stigma associated with the behaviour. This could cause a potential overestimation of the relationship between anticipated stigma and unmet need. The findings are limited to married youth in Ethiopia and thus are not generalizable to other populations such as unmarried sexually active youth or to other country contexts.

Despite these limitations, the anticipated stigma index does appear to be a valid and reliable measure that could be replicated and tested in other contexts and among other populations. Longitudinal research could show how the anticipated stigma index influences future service use and contraceptive use behaviours. Another area of research that is noteworthy is to explore why and how FP users who reported anticipated stigma overcome barriers. This information would enable programmes to better design interventions that support married youth who experience stigma and are not using voluntary family planning.

\footnotetext{
Acknowledgments. The authors thank Lemi Negeri, who served as a research coordinator during this study. They also sincerely thank Mihira Karra, Erika Martin, Erika Houghtaling and Rabab Pettitt of USAID for their useful feedback on the manuscript. The manuscript benefited from the feedback at the Population Association of America meeting held in Chicago, Illinois, US, in April 2017, where it was presented as an oral presentation. They would also like to acknowledge and thank the research assistants and drivers who collected the data in Ethiopia, and are deeply grateful to the youths who participated in the study and shared their time and experiences.
}

Ethical Approval. Free and informed consent was obtained from all respondents. Younger girls provided their assent and informed consent was obtained from an adult guardian in the household. This study received ethical approval from the Population Council Institutional Review Board and the Ethiopian Public Health Institute. The authors assert that the study complies with the Helsinki Declaration of 1975, as revised in 2008. 
Conflicts of Interest. The authors have no conflicts of interest to declare.

Funding. The Evidence Project is made possible by the generous support of the American people through the United States Agency for International Development (USAID) under the terms of cooperative agreement No. AIDOAA-A-13-00087. The contents of this manuscript are the sole responsibility of the Evidence Project and Population Council and do not necessarily reflect the views of USAID or the United States Government.

\section{References}

Abajobir AA and Seme A (2014) Reproductive health knowledge and services utilization among rural adolescents in east Gojjam zone, Ethiopia: a community-based cross-sectional study. BMC Health Services Research 14, 138.

Abebe M and Awoke W (2014) Utilization of youth reproductive health services and associated factors among high school students in Bahir Dar, Amhara Regional State, Ethiopia. Open Journal of Epidemiology 4(2), 69-75.

Adams MK, Salazar E and Lundgren R (2013) Tell them you are planning for the future: gender norms and family planning among adolescents in northern Uganda. International Journal of Gynecology \& Obstetrics 123 (Supplement 1), e7-e10.

Ayehu A, Kassaw T and Hailu G (2016) Level of young people sexual and reproductive health service utilization and its associated factors among young people in Awabel district, Northwest Ethiopia. PLoS One 11(3), e0151613.

Bautista RED, Shapovalov D and Shoraka AR (2015) Factors associated with increased felt stigma among individuals with epilepsy. Seizure 30, 106-112.

Bender SS and Fulbright YK (2013) Content analysis: a review of perceived barriers to sexual and reproductive health services by young people. European Journal of Contraception \& Reproductive Health Care 18(3), 159-167.

Biddlecom AE, Hessburg L, Singh S, Bankole A and Darabi L (2007a) Protecting the Next Generation in Sub-Saharan Africa: Learning from Adolescents to Prevent HIV and Unintended Pregnancy. Guttmacher Institute, New York, p. 16.

Biddlecom AE, MunthalI A, Singh S and Woog V (2007b) Adolescents' views of and preferences for sexual and reproductive health services in Burkina Faso, Ghana, Malawi and Uganda. African Journal of Reproductive Health 11(3), 99-100.

Bradley S, Croft TN, Fishel JD and Westoff CF (2012) Revising Unmet Need for Family Planning. DHS Analytical Studies No. 25. ICF International, Calverton, MD.

Brewis A, Trainer S, Han S and Wutich A (2017) Publically misfitting: extreme weight and the everyday production and reinforcement of felt stigma. Medical Anthropology Quarterly 31(2), 257-276.

Bruce J and Chong E (2006) The Diverse Universe of Adolescents, and the Girls and Boys Left Behind: A Note on Research, Program, and Policy Priorities. United Nations Millennium Project, New York.

Butt G, Paterson BL and McGuinness LK (2007) Living with the stigma of hepatitis C. Western Journal of Nursing Research 30(2), 204-221.

Central Statistical Agency and ICF (2016a) Ethiopia Demographic and Health Survey 2016. Central Statistical Agency (CSA) [Ethiopia] and ICF, Addis Ababa, Ethiopia, and Rockville, MD.

Central Statistical Agency and ICF (2016b) Ethiopia Demographic and Health Survey 2016 [Dataset]. ETIR70FL.DTA. Central Statistical Agency (CSA) [Ethiopia] and ICF [Producers] and ICF [Distributor], Addis Ababa, Ethiopia, and Rockville, MD.

Chambers LA, Rueda S, Baker DN, Wilson MG, Deutsch R, Raeifar E et al. (2015) Stigma, HIV and health: a qualitative synthesis. BMC Public Health 15, 848.

Chandra-Mouli V, Mapella E, John T, Gibbs S, Hanna C, Kampatibek N and Bloem P (2013) Standardizing and scaling up quality adolescent friendly health services in Tanzania. BMC Public Health 13, 579.

Cockrill K, Upadhyay UD, Turan J and Greene Foster D (2013) The stigma of having an abortion: development of a scale and characteristics of women experiencing abortion stigma. Perspectives on Sexual and Reproductive Health 45(2), 79-88.

Coffey P, Leitenberg H, Henning K, Turner T and Bennett RT (1996) Mediators of the long-term impact of child sexual abuse: perceived stigma, betrayal, powerlessness, and self-blame. Child Abuse \& Neglect 20(5), 447-455.

Corrigan P (2004) How stigma interferes with mental health care. American Psychologist 59(7), 614-625.

Denno DM, Hoopes AJ and Chandra-Mouli V (2015) Effective strategies to provide adolescent sexual and reproductive health services and to increase demand and community support. Journal of Adolescent Health 56(1) (Supplement), 22-41.

Erulkar A, Medhin G and Weissman E (2017) The Impact and Cost of Child Marriage Prevention in Three African Settings. Population Council, Addis Ababa and New York.

Erulkar A and Muthengi E (2009) Evaluation of Berhane Hewan: a program to delay child marriage in rural Ethiopia. International Perspectives on Sexual and Reproductive Health 35(1), 6-14.

Gelman A, Rosenfeld EA, Nikolajski C, Freedman LR, Steinberg JR and Borrero S (2017) Abortion stigma among lowincome women obtaining abortions in western Pennsylvania: a qualitative assessment. Perspectives on Sexual and Reproductive Health 49(1), 29-36.

Goffman E (1963) Stigma: Notes on the Management of Spoiled Identity. Prentice-Hall, Englewood Cliffs, NJ. 
Hall KS, Manu A, Morhe E, Challa S, Loll D, Dozier J et al. (2015) Understanding “Bad Girl:" Qualitative Findings on Stigma and Adolescent Sexual and Reproductive Health in Ghana. Population Association of America, Washington, DC.

Hall KS, Manu A, Morhe E, Harris LH, Loll D, Ela E et al. (2017) Development and validation of a scale to measure adolescent sexual and reproductive health stigma: results from young women in Ghana. Journal of Sex Research 55(1), $60-72$.

HIPs (2015) Adolescent-Friendly Contraceptive Services: Mainstreming Adolescent-Friendly Elements into Existing Contraceptive Services. High Impact Practices in Family Planning, United States Agency for International Development, Washington, DC.

Iverson AC, van Staden L, Hughes JH, Greenberg N, Hotopf M, Rona R J et al. (2011) The stigma of mental health problems and other barriers to care in the UK Armed Forces. BMC Health Services Research 11, 31.

Jain A, Ismail H, Tobey E and Erulkar A (2017) Understanding Adolescent and Youth Sexual and Reproductive Health-Seeking Behaviors in Ethiopia: Implications for Youth Friendly Service Programming. Population Council, Washington, DC.

Jain AK, Obare F, RamaRao S and Askew I (2013) Reducing unmet need by supporting women with met need. International Perspectives on Sexual and Reproductive Health 39(3), 133-141.

Jiménez J, Puig M, Ramos JC, Morales M, Asencio G, Sala AC et al. (2010) Measuring HIV felt stigma: a culturally adapted scale targeting PLWHA in Puerto Rico. AIDS Care 22(11), 1314-1322.

Kennedy EC, Bulu S, Harris J, Humphreys D, Malverus J and Gray NJ (2013) "Be kind to young people so they feel at home": a qualitative study of adolescents' and service providers' perceptions of youth-friendly sexual and reproductive health services in Vanuatu. BMC Health Services Research 13, 455.

King M, Dinos S, Shaw J, Watson R, Stevens S, Passetti F et al. (2007) The Stigma Scale: development of a standardised measure of the stigma of mental illness. British Journal of Psychiatry 190(3), 248-254.

Kish L (1949) A procedure for objective respondent selection within the household. Journal of the American Statistical Association 44(247), 380-387.

Lekas HM, Siegel K and Leider J (2011) Felt and enacted stigma among HIV/HCV-coinfected adults: the impact of stigma layering. Qualitative Health Research 21(9), 1205-1219.

Loewenthal KM (2001) An Introduction to Psychological Tests and Scales. Psychology Press, East Sussex.

MacQuarrie KLD (2014) Unmet Need for Family Planning among Young Women: Levels And Trends. DHS Comparative Reports No. 34. ICF International, Rockville, MD.

Matsunaga M (2015) How to factor-analyze your data right: do's, don'ts, and how-to's. International Journal of Psychological Research 3, 97-110.

Mekbib T, Erulkar A, and Belete F (2005) Who are the targets of youth programs: results of a capacity building exercise in Ethiopia. Ethiopian Journal of Health Development 19(1), 60-62.

Mmari KN and Magnani RJ (2003) Does making clinic-based reproductive health services more youth-friendly increase service use by adolescents? Evidence from Lusaka, Zambia. Journal of Adolescent Health 33(4), 259-270.

Motuma A, Syre T, Egata G and Kenay A (2016) Utilization of youth friendly services and associated factors among youth in Harar town, east Ethiopia: a mixed method study. BMC Health Services Research 16, 272.

Murray SM, Augustinavicius J, Kaysen D, Rao D, Murray LK, Wachter K et al. (2018) The impact of Cognitive Processing Therapy on stigma among survivors of sexual violence in eastern Democratic Republic of Congo: results from a cluster randomized controlled trial. Conflict and Health 12, 1.

Muthengi E and Erulkar A (2011) Delaying Early Marriage among Disadvantaged Rural Girls in Amhara, Ethiopia, through Social Support, Education, and Community Awareness. Population Council, New York.

Netemeyer RG, Bearden WO and Sharma S (2003) Scaling Procedures: Issues and Applications. Sage Publications, Thousand Oaks, CA.

Norris A, Bessett D, Steinberg JR, Kavanaugh ML, De Zordo S and Becker D (2011) Abortion stigma: a reconceptualization of constituents, causes, and consequences. Women's Health Issues 21 (Supplement 3), 49-54.

Nyblade L, Stockton M, Nyato D and Wamoyi J (2017) Perceived, anticipated and experienced stigma: exploring manifestations and implications for young people's sexual and reproductive health and access to care in North-Western Tanzania. Culture, Health \& Sexuality 19(10), 1092-1107.

Overstreet NM and Quinn DM (2013) The intimate partner violence stigmatization model and barriers to help seeking. Basic \& Applied Social Psychology 35(1), 109-122.

Parker R and Aggleton P (2003) HIV and AIDS-related stigma and discrimination: a conceptual framework and implications for action. Social Science \& Medicine 57(1), 13-24.

Pathfinder International (2012) Bringing Youth-Friendly Services to Scale in Ethiopia. Pathfinder International, Addis Ababa.

Pathfinder International (2016) Youth Friendly Services: Piloting to Scaling-up in Ethiopia. Pathfinder International, Addis Ababa.

Puhl RM and Heuer CA (2010) Obesity stigma: important considerations for public health. American Journal of Public Health 100(6), 1019-1028. 
Quinn D M and Chaudoir SR (2009) Living with a concealable stigmatized identity: the impact of anticipated stigma, centrality, salience, and cultural stigma on psychological distress and health. Journal of Personality and Social Psychology 97(4), 634-651.

Richardson E, Allison KR, Gesink D and Berry A (2016) Barriers to accessing and using contraception in highland Guatemala: the development of a family planning self-efficacy scale. Open Access Jornal of Contraception 7, 77-87.

Rivera R, Mello MCD, Johnson SL and Chandra-Mouli V (2001) Contraception for adolescents: social, clinical and servicedelivery considerations. International Journal of Gynecology \& Obstetrics 75, 149-163.

Scambler G (2004) Re-framing stigma: felt and enacted stigma and challenges to the sociology of chronic and disabling conditions. Social Theory \& Health 2(1), 29-46.

Scambler G and Hopkins A (1986) Being epileptic: coming to terms with stigma. Sociology of Health \& Illness 8(1), 26-43.

Sandelowski M, Lambe C and Barroso J (2004) Stigma in HIV-positive women. Journal of Nursing Scholarship 36(2), $122-128$.

Shaw D (2009) Access to sexual and reproductive health for young people: bridging the disconnect between rights and reality. International Journal of Gynecology \& Obstetrics 106(2), 132-136.

StataCorp (2013) Stata Statistical Software: Release 13. SataCorp, LP, College Station, TX.

Sulemana A, Mumuni A and Badasu DM (2015) Young people's experiences in accessing sexual and reproductive health services in sub-Saharan Africa: a content analysis. Paper presented at the African Population Conference, Johannesburg, South Africa, 2015.

Wahl OF (1999) Mental health consumers' experience of stigma. Schizophrenia Bulletin 25(1), 467-478.

Weiss MG (2008) Stigma and the social burden of neglected tropical diseases. PLoS Neglected Tropical Diseases 2 (5), e237.

Yebei VN, Fortenberry JD and Auyku DO (2008) Felt stigma among people living with HIV/AIDS in rural and urban Kenya. African Health Sciences 8(2), 97-102.

Cite this article: Jain, A. et al. 2018. Stigma as a barrier to family planning use among married youth in Ethiopia. Journal of Biosocial Science 51: 505-519, doi:10.1017/S0021932018000305 